\title{
El pueblo andino y la dialéctica de Dios
}

\author{
Calixto Huanca Cárdenas*
}

Recibido: Marzo 2012 • Aceptado: Mayo 2012

RESUMEN

Este artículo versa sobre la sociedad andina, vertida en dos realidades teológicas: el dios de los Andes centrales y el dios de la cristiandad occidental junto al dios bíblico. Su fin es analizar las razones de su contexto. Tal enfoque reviste un análisis de sus características fundamentales. Este nos conduce a replantearnos los conceptos de libertad, dominación, opresión, realidad teológica andina y realidad ideológica/política, entre otros.

Palabras clave: dios andino, dios colonial, dios bíblico, dominación, opresión.

\section{ABSTRACT}

This article focuses on Andean society, poured in two theological realities, the god of the central Andes and the god of Western Christianity with the biblical God. In order to analyze the reasons for its context. This approach takes an analysis of its key features. This leads us to rethink the concepts of, freedom, domination, oppression, Andean theological reality and reality ideological/ political, among others.

Key words: Andean god, god colonial, biblical God, domination, oppression.

\section{Introducción}

\section{La religión de Pachamama es} una práctica de la fe que sostiene el sistema de vida comunitaria en los Andes centrales (América del Sur). La lucha contra la opresión, la injusticia y el anuncio de la esperanza de Pachakuti de la liberación del pueblo andino es vivencial.

Cuando nos referimos al tema del "pueblo andino y la dialéctica de Dios" de los pueblos de los Andes centrales, nos referimos a los

* Teólogo y filósofo, profesor de Filosofía UNED-UCR. De origen peruano, radica en Costa Rica desde hace 24 años. E-mail: calixto1421@hotmail.com 
pueblos Aymara y Quechua principalmente, descendiente de la cultura milenaria de Tiwanaku ${ }^{1}$.

La descripción analítica será guiada con la "tipología religiosa andina" de Federico Aguiló (1988). La tipología religiosa andina se divide en tres: la religiosidad uránica, que es la fuerza creadora de imperios, élites sociales dominantes y gobernantes desde arriba hacia abajo; la totémica, surgida de los grupos étnicos dominados, que fácilmente fue sustituida por la uránica y luego por la religión católica; y, por último, la tipología religiosa agraria Pachamama, surgida de la base social del pueblo en estrecha relación telúrica y trascendente hasta el pacha cósmico universal que se ha resistido cerca de 500 años y hoy aún está firme y vigente.

Para una explicación más ordenada y lógica, separamos en dos partes: el Dios Pachakuti ${ }^{2}$ en el pueblo andino y el Dios de la cristiandad colonial.

1. Tiwanaku: se llama así a la cultura milenaria más antigua de los Andes y de América. Los descendientes de la cultura milenaria de Tiwanaku son los Aru jaqis, Qullas Aymara y Quechua. Tiwanaku también es el nombre de la ciudad antigua que se encuentra a 60 $\mathrm{km}$ al oeste de la ciudad de La Paz, Bolivia.

2. Pachakuti: vocablo aymara, significa retorno permanente; también se interpreta como renacimiento, liberación y, en términos bíblicos, se podría traducir como jubileo.

\section{El Dios Pachakuti en el pueblo andino}

El análisis acerca del Dios $P a$ chakuti, en el pueblo andino, comprende: la búsqueda de Dios en los Andes centrales y el Dios Pachamama, sostén de la vida comunitaria.

\section{La búsqueda de Dios en los Andes centrales}

Los pueblos Aymara y quechua, de los Andes centrales, viven la búsqueda de Dios con dos desafíos: su búsqueda en la naturaleza y en la historia.

El desafío de la búsqueda de Dios en la naturaleza

El jaqi andino ${ }^{3}$ ha vivido buscando a Dios en las dos dimensiones de la naturaleza: aka uraqina y jaya mik'ayana ${ }^{4}$.

Aka uraqina es el mundo de la tierra, el hábitat del jaqi en los Andes centrales. Este es el lugar donde el jaqi se inquieta sobre la razón de ser de la vida humana, de los animales, de los vegetales

3. Jaqi: vocablo aymara, quiere decir "humanidad", constituida de hombre y mujer o viceversa, es una totalidad que se complementa recíprocamente.

4. Aka uraqina: en aymara, es "el mundo de la tierra o en este mundo de la tierra", relación objeto. Jaya mik'aya es la fuerza de arriba, lejano, celeste, cósmico universal. 
y la existencia misma de la tierra. En esta última, el jaqi encuentra dos lugares distintos: el wak'a y al ina urqi ${ }^{5}$.

El vocablo wak'a, en el idioma Aymara, significa las "manifestaciones de las fuerzas misteriosas" que acontecen en lugares especiales $\mathrm{y}$ en momentos de sorpresa. Por ello, el jaqi andino separa esos lugares con el nombre de Wak'ani, que quiere decir "lugares sagrados", también conocidos como "santuarios". El Wak'ani se identifica en algún espacio del río, del lago, de la piedra, de un árbol o de la montaña, donde se experimenta fuerzas misteriosas capaces de reanimar la vida y crear la fuerza de la fe en la lucha del jaqi, sea hombre o mujer.

El jaqi andino es profundamente religioso, por ello guarda el respeto y hace la devoción a los lugares Wak'ani. La práctica del respeto y la devoción se realiza en los cultos rituales y ceremonias religiosas, teniendo en cuenta que en el lugar de Wak'ani se manifiesta la fuerza de la deidad suprema, identificada como la fuerza de Dios. En relación con la importancia de los hechos y lugares sagrados

5. Wak'a procede del idioma aymara, significa "fuerza misteriosa" y es atribuida a la fuerza de la deidad. Wak'ani, en el mismo idioma, es "lugar sagrado". Ina uraqi es "tierra común" o "profana". en la sociedad, Mircea Eliade (1970: 24) sostiene:

"La heterogeneidad de los hechos sagrados, que turban desde un principio, llega poco a poco a paralizarnos. Porque se trata de ritos, de formas divinas, de objetos sagrados y venerados, de símbolos, de cosmologías, de teologúmenos, de hombres sagrados, de animales, de planetas, de lugares sagrados, etc. $Y$ cada categoría tiene su morfología propia, de una riqueza exuberante e intrincada..."

La práctica ritual del jaqi a los wak'a y la explicación de Eliade de los hechos y lugares sagrados que afectan al hombre en general vive en la búsqueda de Dios, mediante las manifestaciones misteriosas que acontecen en el ambiente mismo de la naturaleza.

Los lugares Wak'ani son conocidos desde el pasado y hasta el día de hoy en diferentes maneras y distintas ocasiones. En el siglo XV, durante el encuentro de los españoles con los andinos, se constataron varios lugares Wak'ani que son comentados por Pierre Duviols (1977), sobre la base de los cronistas coloniales como Ciaza de León. Los santuarios más importantes del incario se encontraron en Timebamba, ciudad de alabanza al Dios Sol, en Tambo Blanco o Janq'u Tampu, en Huamachuco, Ayaviri y Pacura. El culto principal 
de ese tiempo era el Dios Sol, conocido con el nombre de Wiraxocha, el cual se heredó de la religión de Tiwanaku andino.

En la actualidad, encontramos muchos lugares Wak'ani en las cercanías del lago Titiqaqa ${ }^{6}$ y algunos santuarios. El culto al Inti o Sol en la tierra es sustituido por la religiosidad católica con el nombre de "Virgen de Copacaban". Aquel santuario recibe cada fin de semana a centenares de personas de todas las clases sociales, campesinos, comerciantes, estudiantes universitarios y hasta profesionales académicos que van a rendir el culto religioso. El otro santuario es la ciudad de Tiwanaku, donde se encuentra el Templo del Sol, hoy también sustituido con la actividad turística.

Sin embargo, hay lugares Wak'ani aún vigentes. Son sitios especiales conocidos con el nombre de Apacheta, que se encuentran en las altas montañas. El Apacheta es el lugar santo donde se recibe la majestuosidad del Ser Supremo. Sus fuerzas inagotables se relacionan fácilmente entre la tierra y el cosmos universal; es una fuerza trascendente a la que el jaqi rinde culto mediante una serie de ceremonias religiosas y en actitud de humildad.

6. Lago Titiqaqa, se escribe Titicaca, se encuentra entre Perú y Bolivia.
El Apacheta más concurrido actualmente es el santuario de Pachjiri, que se encuentra a $30 \mathrm{~km}$ al este del lago Titiqaqa, en la montaña llamada Jipi.

Los Yatiri (sacerdotes) y las familias Aymara y mestizas acuden cada semana para celebrar el culto con diferentes propósitos: de agradecimiento al Dios Pachamama por la bendición recibida; otras veces, pidiendo el augurio de la salud en casos de enfermedad; asimismo, para la prosperidad de la actividad agrícola, la crianza de ganados y el éxito en los negocios comerciales.

Muchos santuarios de los Apacheta fueron declarados lugares idolatrados y destituidos por la Iglesia Católica en el periodo colonial. Al respecto, Pierre Duviols (1977: 127-128) indica:

"Se refiere a esos montículos de ofrendas que se encuentran en los cruces de los caminos y en lo alto de las montañas. Es a esos dioses de los caminos a los que los viajeros ofrecen coca, maíz, plumas de algunos pájaros, viejas sandalias, o al menos un guijarro, en la creencia de que así se libra de las fatigas del viaje y adquieren nuevo vigor para continuarlo. El cura debe obligar a los habitantes a que ellos mismos destruyan y completamente, las apachetas, en lugar de las cuales se colocará una cruz."

De ese modo, los santuarios o Wak'ani son lugares de encuentro 
entre el jaqi y el Dios Pachamama. El encuentro significa escuchar, confesar, pedir, alabar y renovar la fidelidad. A cambio, el Dios Pachamama ofrece la vida y promete acompañar en todas las actividades cotidianas en la vida del jaqi andino.

En contraste, el lugar de Ina uraqi significa el "lugar común". En otras palabras, se puede considerar como el "lugar profano". De ahí que el jaqi andino, en el ina uraqi usa el campo pastizal, cultiva la agricultura, levanta las viviendas, celebra las fiestas sociales; en fin, es un espacio de actividad cotidiana, según la concepción del jaqi en los Andes centrales.

En el pensamiento del jaqi andino, el ina uraqi posee lugares yanq'ani, que quiere decir "lugares demoniacos", o sea, hay sitios temidos por el jaqi, precisamente porque en momentos de soledad y en lugares desérticos, en alguna hora del día, de repente aparece la imagen de algún animal como el perro, el caballo o también puede ser la gente, y luego desaparece inexplicablemente. Desde ese momento, la persona que vio aquel fenómeno especial, se enferma y muchas veces muere.

Los tres elementos del pensamiento del jaqi, el Wak'ani (sagrado), el ina uraqi (lugar profano) y el yanq'ani (lugar demoniaco), nos hacen comprender el concepto de la santidad atribuida a Dios, el concepto profano y el concepto del mal o demonio.

Pero lo más interesante es que el jaqi andino no se queda estático, sino en el dinamismo permanente religioso de la búsqueda de Dios, en el ambiente mismo de la naturaleza donde vive. En ese ambiente natural de la tierra, llega a comprender la trascendencia de Dios como resultado de la propia intuición de la vida y en estrecha relación telúrica, lugar de donde surge la idea de Pachamama como el nombre de Dios. El jaqi y el uraqi se proyectan hacia Jaya mik'aya ${ }^{7}$ o sea, que el hombre y la tierra son inseparables y se proyectan hacia el cosmos universal. De ahí que la religión Pachamama surge de la base social mediante las manifestaciones de la tierra y gobierna hasta el cosmos infinito. Veamos, entonces, el concepto andino de mundo celeste.

La dimensión de Jaya mik'aya es otro concepto donde el jaqi busca a Dios. Las palabras jaya mik'aya son del idioma Aymara y significan "lejano celeste", que se manifiesta desde arriba para abajo o desde lo lejano hasta la vivencia. Esas manifestaciones son la lluvia, el trueno, la luna, las estrellas, el sol o Inti.

El jaqi andino piensa que la tierra y el cosmos están íntimamente

\footnotetext{
7. Jaya es vocablo aymara, significa lejano, infinito, espacio. es "cielo, celeste, cosmos".
} 
relacionados, por ello la idea de Pachamama como una fuerza de la deidad suprema que une y gobierna: el significado de pacha es el "cosmos" y el de mama se atribuye a la tierra como "madre tierra"; entonces, la que hace mover o anima la existencia es una fuerza suprema, Pachamama. De modo que en el pensamiento del jaqi andino, de hecho, se elimina la idea de un Dios uránico que gobierna desde lejos y, cada vez, está más madura la idea de un Dios presente y actuante desde la relación de hombre-tierra, que trasciende hasta el cosmos infinito y universal.

Sin embargo, en la época del Inkario, el culto del Sol fue bastante desarrollado, precisamente por los gobernantes de la distinta Inka como Huascar y Atahualpa, en el Tawantisuyu ${ }^{8}$. De esa religión uránica del Sol, Mircea Eliade (1970: 156) nos dice:

"Si tenemos en cuenta que en el otro lado del Atlántico el culto solar no se desarrolló más que en Perú y México, es decir, en los dos únicos pueblos americanos civilizados, en los únicos que alcanzaron el nivel de una auténtica organización politica, caeremos en la supremacía de las hierofanías solares y los destinos históricos. Se diría que el sol predomina alli donde, gracias a los reyes,

8. Tawantinsuyu significa 4 Estados Comunitarios Andinos. a los héroes, a los imperios, está en marcha la historia..."

En conclusión, en el pensamiento del jaqi andino hay dos modos de interpretar la búsqueda de Dios en la naturaleza: el Dios que surge desde la base social-tierra, como lo es Pachamama, y el Dios que brota desde el lejano celeste, como lo es el Sol, reconocido por los gobernantes. Con esa premisa, pasamos al análisis de la búsqueda del Dios en la historia.

\section{El desafío de la búsqueda de Dios en la historia}

El pueblo andino vive en larga jornada histórica; pero, lamentablemente, los acontecimientos ocurridos no están registrados en documentos por razones de interrupción y la opresión colonial española, por la continuidad opresiva republicana y la escasez de investigación científica.

Sin embargo, hoy contamos con las tradiciones orales, los testimonios arqueológicos, los documentos aborígenes, los textos de los cronistas coloniales y la contribución de las ciencias sociales en los últimos años.

Una de las tradiciones orales es la Paqariña ${ }^{9}$, que relata sobre el

9. Paqariña, del vocablo aymara, significa aurora del amanecer, génesis, comienzo y mito. 
origen de la vida humana, el mundo y la existencia de Dios en la historia andina. Según esas tradiciones orales, el jaqi andino cree que son los descendientes de la cultura milenaria de Tiwanaku porque, así contaron el Paqariña de los abuelos.

Tiwanaku es la antigua ciudad de los Qulla, convertida hoy en un centro turístico. Las ruinas arqueológicas de por sí dan el testimonio de una cultura y civilización muy desarrolladas, producto de la mente y la mano del jaqi de los Andes centrales. Al respecto, Arturo Posnansky (1945: 86-87) nos dice:

"No podía ser de otro modo, ya que el hombre, con el transcurso del tiempo, se ha aprovechado de la ciencia, de la experiencia y sabiduría de sus antecesores, y ha procurado superarse más y más. Asi ha sido también el Tiahuanaco, donde continuamente se producian nuevos inventos, surgían nuevos métodos, se generaban nuevas ideologías en la teología cosmológica, en la científica, en el arte y en los sistemas agrícolas.

El hombre de entonces ha continuado ascendiendo peldaño por peldaño, hasta llegar ya cerca de la cúspide de la cultura, instante en el cual un supremo poder mandó: ¡Alto ahí! Y las aguas del gran lago se precipitaron sobre la floreciente y maravillosa ciudad que provocaba la envidia de los dioses, mientras los habitantes se hallaban en activismo y febril trabajo. Cayeron los brazos del artífice que cincelaba la famosa puerta del sol. El volcán Kjappia, que se halla a unos sesenta kilómetros al frente de la metrópoli, arrojó torrentes de agua candente, de fuego y ceniza y así, en pocas horas, sucumbió una portentosa cultura que había necesitado milenios para generar. ;Sio transit gloria mundi!"

La historia de la cultura y la civilización de Tiwanaku continúa hasta el día de hoy, a pesar de las dificultades, de los fenómenos naturales, del terremoto, de las sequías y las inundaciones por un lago. Y por otro, las interrupciones del proceso de desarrollo histórico causadas por la invasión y la colonización española, desde el año 1532, con la ocupación de Cajamarca y el asesinato de Atahuallpa, conforme indican las referencias de Alfred Metraux (1975).

De ese modo, podemos entender que el jaqi andino tiene su propia visión de la Paqariña. Cree que sus antepasados amanecieron en las riberas del lago Titiqaqa, que allí levantaron la civilización de Tiwanaku, construyeron templos y adoraron al dios Pachamama, porque es dador de los frutos de la tierra y el calor solar de cada día. Desde entonces, creyeron que la vida humana, la de los animales, los vegetales, la tierra y el cosmos universal obedecen a la acción creadora de una deidad suprema. 
Por ello, en el pensamiento del pueblo andino, existe la estrecha relación entre el hombre, la tierra, el cosmos y Dios.

Ahora bien, la búsqueda de Dios se hace en ese gran desafío de la historia, de la cultura y la civilización de Tiwanaku, pasando por la historia inkaika, la opresión colonial y la época republicana de nuestros tiempos. En ese proceso de la historia, se ha buscado a Dios con distintos nombres y en distintos idiomas y culturas; principalmente, en los Aymara y quechua en los Andes centrales.

María Rostworowsky de Diez Canseco, en su obra Estructuras andinas del poder (1988), analiza las estructuras mitológicas de los dioses, la ideología religiosa y el poder.

Los dioses mayores son: Tunupa, que se manifiesta en el fuego, en el volcán y en la lluvia; y Viracocha, que se manifiesta en el Inti o Sol; Illapa se revela en el rayo, en el trueno y en el relámpago; Pachamac es el Dios supremo; Pariacaca se muestra en la lluvia torrencial y el rayo; Guari se conoce en la abundancia de la agricultura; Libiac es Dios del rayo y trueno; Catequil y Piguerao es una pareja de la divinidad celeste relacionada con el rayo, el relámpago, el trueno y la lluvia; Chicopaec y Aiapaec es otra pareja de la divinidad masculina y está asociada con las fuerzas celestes del sol que anima a las plantas.
Los dioses menores son: Timayricapa y Timayhananpe, héroes civilizadores de Chinchaycocha y el cerro de Pasco, caídos del cielo, considerados como curacas, guerreros y conquistadores; Raco y Rananolca son grandes cerros de Chinchaycocha, dador de las comidas y buenos sembradíos; Yanaraman y Libiac Cancharco, el primero caído del cielo como un niño y el segundo, como un globo y convertido en cerro. Ellos son los dioses locales y antepasados deificados.

Las diosas y parejas divinas son deidades femeninas como Urpay Huachac y Auca Atama, consideradas como venidas del mar; la primera trae la lluvia y la segunda conserva la salud y provee buenas cosechas. Cóndor Tocas y Coya Huarmi son divinidades de Cajatambo. El Cóndor Toca fue considerado nacido del mar y convertido en cóndor, que llegó junto con su hermana Coya Huarmi al pueblo de Mangas.

El análisis de la religión andina de María Rostworowsky de Diez Canseco (1988) está basado, fundamentalmente, en los documentos de los cronistas coloniales. Como resultado de ello, aparecen varios dioses con nombres propios, dioses mayores y dioses menores, masculinos y femeninos, e inclusive afirmaciones de que en el pueblo andino no existió el concepto abstracto de Dios. 
Sin embargo, tenemos dos observaciones: las contradicciones y las coincidencias en la búsqueda de Dios, según los cronistas coloniales. Las contradicciones se detectan en la recapitulación, cuando María Rostworowsky de Diez Canseco (1988: 180) dice que:

"Los conquistadores, ávidos de oro, se preocuparon más bien en probar los derechos del rey de España a esas nuevas tierras y en evangelizar a los naturales, manipulando los esquemas religiosos y políticos con el objeto de adaptarlos y acomodarlos a sus propios fines."

Las manipulaciones de los esquemas religiosos y políticos por parte de los conquistadores coloniales, significa que han interpretado la religión andina según sus valores culturales y, sobre todo, según la fe cristiana con la que llegaron en el siglo XV. Después de esa crítica de la manipulación colonial, María Rostworowsky de Diez Canseco (1988: 180) afirma que en el pueblo andino:

"No existió el concepto abstracto de Dios. A los Dioses se les designaba por sus nombres propios y poseían el término huaca, voz quechua y Aymara, para señalar lo sagrado, el ídolo y el santuario. El mismo sentido tenia la voz machoec en idioma yunga o mochica (Fernando de la Carrera 1644)."
De modo que, entonces, según el pensamiento del pueblo, en los Andes centrales hubo la manipulación de los españoles sobre la religión en la época de la Colonia $y$, posteriormente, en la Republicana. En cuanto a la existencia de varios nombres y varios dioses, es discutible, porque en los mismos cronistas coloniales existen las coincidencias de un solo nombre de la religión.

Las coincidencias de los cronistas coloniales en asignar un solo nombre a la deidad incaica se expresa en que, para Bertonio Ludovico (1602), la deidad principal se llamaba Tunnupa o Thunupa; Ramos Gavilán (1621) le dice Tunupa; Santa Cruz Pachacuti (1613) lo llama Tonopa o Tarapaca; Cieza de León (1553) le dice Tuapaca; Juan Maldonado (1561) también menciona Thunupa. Otra vez, Cieza de León (1553) levanta el nombre de Tici Viracocha; la cultura Colla lo denominaba Tuapaca; mientras Sarmiento de Gamboa (1532), era conocido como Taguapaca que acompañaba a Viracocha Pachayachachic (Dios hacedor del mundo); Betanzos (1576) menciona el nombre de Tici Viracocha, venido de Tiwanaku; y Acosta (1600) dice que es Viracocha, nombre supremo de Dios, después el sol y luego, el trueno. 
El otro nombre más importante ha sido Pachacamac, como la deidad suprema, a veces confundida con la Quya Mama o Quya Warmi, como la hermana de Cóndor Tocas y, sin duda, que se refiere a la deidad de Pachamama.

En conclusión, los cronistas españoles trataron de interpretar el concepto andino de Dios y buscaron el nombre, aun con el riesgo de adulterar la estructura lingüística. Pusieron varios nombres, pero en realidad se trataba de una deidad principal que era Viracocha, conocida también como Tunupa; más correctamente suena como $\mathrm{Wi}$ raxocha, refiriéndose al Sol o Inti. Por lo tanto, el Inti era la religión de Inkario. Una religión uránica, de arriba, desde el celeste. Y la otra concepción o tipo de la religión andina era Pachamama, desde la relación del jaqi, uraqi, mik'aya.

Nuestra conclusión está respaldada, precisamente, por las prácticas religiosas de la actualidad en la zona central de los Andes; lugar donde la gente o jaqi recuerda con mucha devoción a Inti, a pesar de la sustitución por la religión cristiana a manera de sincretismo religioso; pero la religión más importante es Pachamama, firme y vigente.

El resultado de otras investigaciones acerca de la búsqueda de Dios en la historia andina clarifica cada vez con más objetividad.
Entre ellas, tenemos a Arturo Posnansky (1945), quien investigó por más de cuatro décadas el caso de Tiwanaku y nos refiere sobre dos cultos religiosos: el culto Aymara, más antiguo y el culto Qiswa posterior. En el culto Aymara se conocen los nombres de Tunnupa o Pachaachachi o Pachacamac o Pachatata. En el culto Qiswa se llaman Huirajocha o Titi Huirajocha o Tisi Huirajocha. J. Alden Mason (1961: 162 ), otro investigador de la cultura andina, en relación con la vida religiosa del Inka, sostiene una religión monoteísta:

"Los incas fueron adoradores del sol, el sol, Inti, era la deidad principal y el progenitor de la dinastía real, aunque los sacerdotes y las mujeres escogidas servían a todos los dioses, el sol destacaba tanto respecto a los demás, con los cronistas siempre se refería a estas mujeres como las vírgenes del sol y a los santuarios como templos del sol."

Del mismo modo, las investigaciones del Centro de Estudios y Publicaciones de Perú (1982), comentan acerca de la actitud de Atahualpa, que se negó a la fe cristiana y se identificó con la religión del Sol. El relato es referido por el cronista Francisco de Jerez y dice que el fraile Vicente de Valverde leyó la sentencia para Atahualpa con el crucifijo en una mano y el 
breviario en la otra. Mediante ese documento oficial, exigió la renuncia a la idolatría y sumisión al rey de España. Después de la lectura y la traducción del quechua, el Inka negó ser vasallo de ningún hombre y prefirió tratar al emperador como un hermano, por más poderoso que fuera. En cuanto al papa, lo calificó de loco por el deseo de regalar países que no le pertenecían e insistió en que no cambiaría su fe. A propósito, le mostró el sol para indicar que vivía y, en cambio, el Dios cristiano estaba muerto.

Otro nombre frecuentemente repetido hoy es el de Apu Qullama $A w k i$, el cual quiere decir "señor Dios padre". Esa terminología, creemos, es una traducción del cristianismo al Aymara.

En conclusión, diremos que la búsqueda de Dios en la naturaleza tiene dos dimensiones: la dimensión de abajo para arriba, o sea, la concepción divina que surge de la base social en relación directa con la madre tierra y abarca al Sol y al cosmos universal que sugiere el nombre de Pachamama. Y la dimensión de arriba hacia abajo o del celeste hacia nuestra vida social, que tiene relación estrecha del Inti o Sol, el cual domina al cosmos, luego a la tierra y a la vida humana constituida en los pueblos.

Por otro lado, también diremos que es posible entender la búsqueda de Dios en la historia en sus dos dimensiones: la dimensión atribuida a los guerreros, los vencedores y gobernantes del poder político y social. Así como los gobernantes Inkairos, que adoraron al Dios Inti y con esa fuerza mantuvieron el gran estado de Tawantinsuyu. En cambio, desde la dimensión de la base social del pueblo, la religión ha sido una institución mítica desde la Paqariña, esa fuerza le ha dado la constitución del Ayllu Marka ${ }^{10}$, con él se unió la fuerza telúrica, juntos con el cosmos, y se estableció el nombre divino de Pachamama. Desde entonces, el Ayllu Marka o pueblo andino lucha en la resistencia y se proyecta hacia la liberación con la fuerza de la fe de Pachamama, que desarrollaremos más ampliamente adelante.

\section{El Dios Pachamama, Pachakuti de la vida comunitaria}

El pueblo andino vive con la fuerza de Pachamama; esta ha sostenido la historia de la lucha por la resistencia y el Pachakuti de la liberación de vida comunitaria. Por ello, desarrollaremos el concepto andino de Pachamama,

\footnotetext{
10. Ayllu: vocablo aymara, significa célula social, comunidad mina-estado y sociedad comunitaria. Es pueblo, nación o ciudad y estado.
} 
jakkiri cusisiñana yupaychiri y Yatiri Marka irpiri ${ }^{11}$.

\section{El concepto andino} de Pachamama

El Dios Pachamama es un sujeto social, es el jaqi, vocablo Aymara que significa "humanidad". Está constituido de chacha, que es "hombre", y Warmi, que es "mujer". El jaqi en plural es jaqinaka, y quiere decir "unidades familiares" o la "gran familia de descendencia genealógica". De ahí que las unidades familiares referidas se denominan el Ayllu Marka. De este modo, entonces, en el pensamiento del pueblo andino hay un concepto de la totalidad como el jaqi y el Ayllu Marka, unidades familiares. La sociedad comunitaria y participativa es el sujeto social del Dios Pachamama.

También vamos a aclamar que en el pensamiento del jaqi andino existe la idea de jaqi jakaña, cuyo significado es "solo la vida es capaz de generar la vida". Por ello, el jaqi andino es amante de la vida, porque sabe que la vida de los animales, de los vegetales, el agua, el sol y el oxígeno permite el jaqi jakañama, es decir, la relación de la vida humana en plenitud.

11. Traducción: Liturgia de vida festiva. Sacerdote, guía del pueblo.
Pero esa vida que nace y se desarrolla en la naturaleza ciertamente obedece a una instancia superior, de donde proviene la misma existencia de la vida que es atribuida a una divinidad trascendente y suprema, la cual es reconocida por el jaqi andino con el nombre de Pachacamac o Pachamama. De ahí surge la pregunta: ¿cómo se entiende el sentido de Pachacamac o Pachamama? Vamos a explicarlo en dos vías: la de la reducción y en el sentido trascendente.

En el sentido de la reducción, tomaremos los siguientes elementos: Mamaispalla, Quyamama, tierra, Mamakilla y María, madre de Jesús.

El pueblo andino guarda mucho respeto a Mamaispalla, porque es considerada como una fuerza espiritual que vela y cuida el mundo de las sementeras agrícolas y campos pastizales. En su condición de fuerza espiritual, también es como una madre de voluntad inquebrantable, porque previene las necesidades básicas, reserva las energías organizadas de la tierra, impulsa la maduración de los productos y, finalmente, proporciona alimentos al jaqi o pueblo andino. Con razón, Mauricio Mamani P. (1988: 77) reproduce el relato de Víctor Ocho cuando indica:

"Ispalla es como el espiritu que vela por las chacras o los productos. Es 
el espiritu que genera la producción de las diferentes sementeras.

Ispalla o los diferentes frutos alimenticios son considerados como hijos de la wirjina o Pachamama. Todos los pastos o plantas maman la leche de la Pachamama."

Lo interesante es que en el pensamiento del pueblo andino existe una relación cuadripartita entre el jaqi, Mamaispalla, los productos agrícolas y la tierra. Ello significa que el jaqi o humanidad andina confía en que Mamaispalla es una fuerza que anima a la tierra; por eso, ella da buenos frutos agrícolas para la alimentación del pueblo andino. Como resultado de esa situación, la vida del jaqi continúa desarrollándose en la historia.

En efecto, quien cree que Mamaispalla es Pachamama, está haciendo una reducción del concepto de Pachamama, porque Mamaispalla simplemente es la protección de fuerza espiritual de los productos agrícolas, y Pachachamama es totalizante como es la madre tierra.

En cuanto a la Quyamama, viene de dos vocablos del idioma Aymara: la voz Quya, que interpreta en sus dos sentidos como "semilla virgen y la tierra nueva", y la voz Mama, como "Madre".

El sentido de la semilla virgen se relaciona estrechamente con la persona humana de sexo femenino. Se trata de la $\tilde{N} u s t a^{12}$, joven mujer virgen que reina la vida y la dignidad de la mujer, pero dispuesta a generar nuevos seres humanos. $Y$ el sentido de la semilla virgen también está relacionado con la semilla de los frutos agrícolas, con todas las capacidades reproductivas de la abundancia que luego sirve de alimento para los seres humanos y los animales.

El sentido de la tierra nueva se denomina con el nombre de Puruma. Quiere decir tierra virgen, llena de energías orgánicas y lista para generar los productos agrícolas y, de esa manera, conservar el desarrollo de la vida humana.

Por su parte, la voz mama es la madre que asume la responsabilidad de cuidar, velar y alimentar a sus criaturas las cuales, en ese caso, son los jaqi y los animales.

Entonces, la Quyamama es la fuerza de la virginidad femenina, la fuerza de la fertilidad de los productos agrícolas y la fuerza de las energías orgánicas de la tierra, la cual se interpreta como una totalidad materna que reproduce la nueva vida y en forma permanente.

En consecuencia, Pachamama no se puede reducir en el sentido de la Quyamama, precisamente porque todas las funciones y limitaciones de esta son rebasadas por la fuerza de Pachamama.

12. Nusta: voz aymara, significa reina, joven y virgen o doncella, se considera mujer completa en el Ayllu Marka. 
Mamakilla también se llama Phaxsimama, y este es el nombre atribuido a la "Luna madre". La Phaxsimama es el signo celeste que regula el tiempo de la fecundidad femenina, tanto en la mujer como también en los animales y el ciclo agrícola. A este respecto, Mauricio Mamani P. (1988) reproduce el relato de las fases de la Luna de Víctor Ochoa. Las fases de la Luna son cuatro: Wawa phaxsi es luna nueva, Sunaqi se refiere al cuarto creciente y al cuarto menguante, Urt'a es luna llena y Jairi ch'amaka es luna desaparecida.

De modo que Mamakilla o Phaxsimama es como una madre que conoce el tiempo y regula los periodos de gestación y el ciclo agrícola, según el pensamiento del Jaqi en los Andes centrales.

Por lo tanto, la fuerza de Pachamama no está todavía a la altura de Mamakilla o Phaxsimama, porque trasciende al más allá de la Luna celeste en el cosmos universal.

Ahora bien, explicaremos el sentido de la tierra que ha sido considerado como Pachamama. La pregunta es: ¿por qué razones? Veamos en el pensamiento andino.

La tierra es considerada como la madre que cría, cuida, alimenta y reduce la vida. Hay que guardarle todo respeto y también cuidarla en lo posible. Es un don de la vida, porque ella produce y reproduce los alimentos vegetales, animales y minerales que va generando continuamente la vida humana. Pero la tierra como un don es la manifestación de la deidad suprema de donde surge el ánima de la vida, luego pasa por la tierra y nosotros -los jaqi- disfrutamos la plenitud de esa vida.

Si la tierra es el don de la vida de la deidad suprema, eso significa entonces que es una tierra sagrada, porque ella pertenece al dador de la vida y debe respetarse con devoción, cuidar su integridad y cultivarla adecuadamente para la conservación de la vida humana.

La tierra como madre es don de la vida y sagrada por pertenecer a la deidad suprema; significa que también es el Ayllu Marka. De este modo, no pertenece a individuo alguno sino al Ayllu Marka; por ello, ese pueblo es responsable de su administración en forma equitativa y comunitaria social.

En efecto, la tierra no se puede fraccionar ni se puede negociar, así como no se puede fraccionar al Dador supremo ni al Ayllu Marka, y menos convertirla en objeto de negocio.

Por lo tanto, para el pueblo andino, la tierra ocupa un lugar privilegiado en la historia; es como la madre, como el don de la lluvia, sagrada y entregada para la administración del Ayllu Marka en comunidad. Ante ese pensamiento cuadripartito del pueblo andino en 
relación con la tierra, Oliva Harris y Therese Bouisse Cassagne (en Albó, 1988: 262) comentan:

"La Pachamama es a la vez la divinidad andina más familiar y la más opaca. Su culto es casi universal y abarca no solamente el sector rural sino también las capas populares y urbanas; por su íntima identificación con los campos cultivados y la fertilidad del suelo, su culto celebra sobre todo la abundancia gracias a la cual vivimos como nos enseña el mismo Bertinio."

En consecuencia, la identificación del Pachamama con los campos cultivables y la fertilidad del suelo es una reducción que no es correcta, por cuanto en el pensamiento andino la fuerza de Pachamama trasciende al jaqi, a la uraqi, phaxsi, Inti y todo el cosmos universal. Es cierto que la tierra es la manifestación de la fuerza divina; pero no es todavía, propiamente, Dios mismo.

Por último, debemos indicar que el concepto de Pachamama ha sido reducido y confundido con el nombre de la Virgen María, la madre del Jesús bíblico. La reducción de Pachamama en la madre de Jesús obedece a la política de la evangelización colonial, en la que los santuarios y el nombre de la deidad fueron sustituidos por los santos y la cruz de la cristiandad. Dicha reducción se detecta en las investigaciones y comentarios como el de Alfred Metraux (1973: 226):

"La Paca-mama (La madre tierra) sin duda la principal de todas las divinidades paganas de los cipayas, es confundida constantemente con la virgen, y los indios declaran indiferentemente que la virgen es la madre tierra y que ésta es la virgen. No la conocen bajo el nombre de María sino siempre bajo el de Virxina, que hacer seguir de la palabra tierra (taika). A la Pacamama se le hacen ofrendas de coca, de alcohol, de fetos de llama, y se besa la tierra en señal de respeto hacia ella. No he asistido a ninguna ceremonia que pueda ser considerada como un culto dirigido exclusivamente a su persona."

El concepto andino Chipaya de Pachamama es muy distinto a la Virgen María. Por eso, el Chipaya sigue fiel a su deidad de Pachamama, mientras los evangelizadores creen haber conseguido la sustitución con la Virgen María, cosa imposible. A lo más, se ha conseguido la confusión.

En conclusión, la identificación de Pachamama con Mamaispalla, Quyamama, Mamakilla, Tierra y la Virgen María es una reducción que no corresponde a la cabalidad del pensamiento teológico del pueblo andino. Entonces, veamos el sentido trascendente de Pachamama. 
El sentido trascendente de Pachamama

Este se puede entender a partir de la fe del pueblo andino en relación con la acción de Pachamama en la historia.

Dicha población siempre ha vivido la fe en la acción de Pachamama; esta se ha manifestado en una fuerza de fe y sostén del sistema de vida comunitario.

La fuerza de fe de la vida comunitaria implica todos los aspectos de la historia. Por ello, el uso de la tierra es comunitario, ya que ella es una madre, es el don de la vida, sagrada, porque pertenece a Pachamama y es entregada para la administración del Ayllu Marka.

La fuerza de la fe de Pachamama también es actuante en la vida política del pueblo andino, porque el verdadero guía de los Jilaqata y

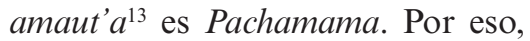
la práctica del gobierno es participativo en el Ayllu Marka.

La vida social andina está basada en el $A y n i^{14}$, como la voluntad suprema. Se constituye una sociedad comunitaria sin clases ni la acumulación de las riquezas individuales: una sociedad comunitaria, solidaria y fraterna.

13. Jilaqata significa autoridad, gobierno. Amaut'a es sabio, filósofo.

14. Ayni significa principio, solidaridad, cooperación mutua, reciprocidad.
Los valores de la cultura como el arte, la lengua y las técnicas de la civilización, a pesar del asalto y la destrucción, se han resistido por cerca de los 500 años, y hoy luchan contra todo tipo de deuda por el Pachakuti de la liberación y de la vida comunitaria.

Por lo tanto, la fuerza de Pachamama se ha manifestado en la relación estrecha del pueblo y la tierra, luego en la luna las estrellas, el sol, y todo el cosmos universal y la mik'aya, infinita. De manera que es un Pachamama de jaqi, uraqi, Inti y mik'aya. Al respecto, Mauricio Mamani P. (1988: 80) sostiene:

“...la Pachamama o madre tierra es cósmica, tiempo, espacio y movimiento; es una realidad viviente y es lo más sagrado; cuida como lo castiga; nos mantiene sanos y nos conduce a la enfermedad; puede darnos vida, como puede resentirse; hay que protegerla para recibir la reproducción; hay que alimentarla para recibir un buen alimento. La madre tierra es fecunda y puede alimentar a sus hijos, como también, por castigo, puede dejar morir de hambre y de sufrimiento."

De ese modo, la fuerza de la fe de Pachamama, además de trascender todos los aspectos históricos, también ha trascendido el espacio geográfico y cultural. Tanto ayer como hoy, esta fe influye a los cuatro puntos cardinales 
del Tawantinsuyu: hacia el Anan (norte) con Ecuador, Colombia y Venezuela en los pueblos qiswa, caribes, guajiro y chibcha; hacia el Unin (sur) de Chile, Argentina y Paraguay, con los pueblos araucano, toba, guaraníes, Aymara y qiswa; hacia el Ch'iqa (este), principalmente con Bolivia y los pueblos urus, chipaya, Qulla Aymara, guaraníes y quechua; y hacia el Kupi (oeste), fundamentalmente con el Perú en los pueblos Aymara y quechua.

En esos países y en sus habitantes la fuerza de Pachamama ha sido y aún sigue siendo vigente y firme. A este respecto, las investigaciones de Federico Aguiló (1988: 75) nos dicen:

"La religiosidad agraria andina en torno a Pachamama es el modelo religioso que más profundamente ha arraigado en la vastedad de los Andes, Abarca concretamente la espacialidad lingüistica de los quechuas, Aymaras y puquinas. Su extensión alcanza el espacio agrario de cuño autóctono de los actuales países: Sur de Colombia, Ecuador, Perú, Bolivia, Chile y Argentina en toda la franja andina. Su antigüedad data aproximadamente de unos 6000 años antes de Cristo..."

En conclusión, el Ayllu Marka, conocido como pueblo andino, que incluye la sociedad andina de hoy, a pesar de la imposición de la religión cristiana por cerca de los 500 años, se resiste y lucha la liberación bajo el aliento de las fuerzas de la fe de Pachamama en relación con la tierra, la historia y el mundo cósmico y universal. Ahora veamos, en adelante, la práctica litúrgica de Pachamama.

\section{Jakkiri cusisiña yupaychiri}

Los vocablos Jakkiri cusisiña yupaychiri provienen del idioma Aymara y tienen el siguiente significado: Jakkiri es "viviendo, vida o vivir", Cusisiña quiere decir "alegría, fiesta, gozo" y Yupaychiri es "alabanza, adoración, celebración cúltica". De ahí que las tres palabras se condensan en: "alabanza festiva de la vida" o "liturgia festiva de la vida".

La Jakkiri cusiña yupaychiri o liturgia festiva de la vida tiene cuatro principios doctrinarios prácticos y son: Waxt'a, Wilancha, Ch'alla y Akulli' ${ }^{15}$. Los cuatro principios doctrinarios son practicados en la celebración litúrgica cultual de Ayllu Marka.

Esos cuatro principios doctrinarios funcionan de manera interrelacionada con una globalidad.

\footnotetext{
15. Waxt'a es rito, ofrenda y culto. Wilancha es el sacrificio de los animales para purificar la vida. Ch'alla es la consagración. Akulli es comunión, vida social, renovación.
} 
Para una comprensión más objetiva, vamos a ilustrar con la celebración litúrgica de Manuel Mamani Ruiz a manera de testimonio.

Manuel Mamani Ruiz es de una familia Aymara. Todos sus integrantes han sido bautizados en la Iglesia Católica. La mayoría de ellos asisten con cierta regularidad a los servicios dominicales y algunos participan en las iglesias protestantes (Metodista y Pentecostal).

Cada año, se celebra la fiesta de Intiraymi, que significa la "fiesta del Inti" o "fiesta del Sol". La fiesta del Sol marca dos acontecimientos importantes: el calendario del año nuevo solar y la celebración del culto agrícola con la "fiesta de la cosecha". Se realiza cada equinoideo de invierno, que cae el 21 de junio.

Para la celebración de la fiesta de Intiraymi, los productos agrícolas ya están recogidos y ellos son: Ch'uqi (papa), jupha (quinúa), Qañawa (pariente de la quinúa), Tarwi (cereal), Ulluku (papaliza), Apilla (oca, izaño, cebada, trigo haba, arveja). Los animales como la Qarwa (llama, alpaca), Wari (vicuña), Wúis (ovino, vacuno, porcino y caballar) son muy aptos para sacrificar.

Los productos agrícolas se separan en cuatro partes: los jás sanos y grandes son separados para la fiesta cúltica; la segunda parte, para la semilla; la tercera, para la alimentación anual; y la cuarta, para comercializar. De una manera similar se opera con los ganados: la primera elección es un animal más sano, gordo y preferentemente el primogénito con destino a la Wilancha cúltica; la segunda selección es para la procreación; la tercera, para la alimentación; y la cuarta está destinada para la comercialización.

A esa cultura del tiempo, llega la víspera de la fiesta de Intiraymi. El anciano Mamani, con la colaboración de su esposa y de su hijo mayor, algunas veces con el Yatiri (sacerdote), asume la función sacerdotal en el año 1980.

La primera actividad es la preparación de los elementos litúrgicos de la eucaristía. Entre ellos, un cordero macho, sano y seleccionado con anterioridad de un año; luego la Juira Quwa (hierba menta), la kuka (coca), Llamp'u (el cebo de la llama), confites, al algodón, el vino, una chuwa (plato de barro) nueva, un Tari multicolor natural (estilo de mantel de la mesa) y todo está preparado.

Llega el día de la fiesta de Intiraymi. El anciano recibe a todos los invitados, que generalmente son familiares, como los abuelos, tíos, primos, hijos, nietos, yernos y vecinos más próximos.

El acto del culto se realiza en un salón grande de la casa. El anciano dirige la ceremonia religiosa, empieza con las palabras de bienvenida y les hace el recuerdo de 
los encargos de sus antepasados inmemoriales sobre la celebración litúrgica en honor a Pachamama, dador de vida de generación en generación. Luego enfatiza que la generación litúrgica es un acto de renovación y fidelidad entre el Ayllu Marka, la tierra y el cosmos universal, los cuales son gobernados por la fuerza de la fe que viene de Pachamama.

Después de la reflexión, se realiza la oración con las siguientes palabras:

Yuspagara qapaq Pachamama, jumatama jakaña churiri aka uraqinsa uqhamaraki qhaya mik'ayansa. Jumana wawanakamaptwa, jakaña churapxakitaya wiñayana wiñayapatak. Pachakuti Tiwasaku. Nanakasti taqi iyausañampiwa, chuymana, amutyna, uqhamarak ch'amampi jumaru yspagarapsmawa, jichhurarunsa, qarurunsa, wiñayana wiñayayapataki.

La traducción dice:

"Gracias Pachamama, así como en universo cósmico, somos tus hijos, siga dándonos la vida en los siglos de los siglos por la eternidad. Los tiempos de Tiwanaku retornan pronto. Nosotros externamos la fidelidad en ti con el corazón, con la mente y la fuerza, hoy mañana y eternamente."
Después de la oración, se cantan las frases: Qulluns pampans jakasiri, ma wawaru uñtasita, Pachamama yupaychani, lo que quiere decir: "En la puna y en el bosque, fraternidad en el vivir, bendición Pachamama".

Acto seguido, se degüella el cordero, cuya sangre se rocía en el espacio sideral, en las paredes de las viviendas y en la tierra en actitud de agradecimiento a Pachamama por la vivienda y los frutos de la tierra. Es un acto eucarístico con el que el jaqi se siente purificado en su vida física, intelectual, social y espiritual. Luego, el plato de la ofrenda y la carne del cordero se colocan sobre el altar, se prende el fuego y se va consumiendo lentamente en horno a Pachamama.

Después de la ofrenda del altar, el anciano coge una jarra de barro cocido llena de agua cristalina o vino y ofrece la Ch'alla, que es rocío de ese elemento líquido que cual lluvia cae en las personas, en la tierra y en todas partes para despertar los vegetales. La tierra se activa para renovar sus energías orgánicas. Y, por último, los presentes, con excepción de los niños menores de 12 años, reciben cada uno cuatro hojas debidamente seleccionadas (q'inthu). Después de las palabras de las recomendaciones, se procede al Akulli, que es el acto de comunión entre personas y 
con Pachamama en la presencia de la tierra.

Cumplido el acto litúrgico, se pasa el banquete de la comida, especialmente preparado y lleno de exquisito sabor. Toda la ceremonia litúrgica se realiza en un espacio de mediodía, comienza como a las 9:00 a.m. y concluye a las 1 p.m.

Los cuatro elementos doctrinarios funcionan inseparablemente en todos los acontecimientos de la vida, pero también cada hecho tiene su propia naturaleza; para ese efecto, uno de los elementos precede con prioridad. Así, para un acto litúrgico de la siembra agrícola, en la colocación de la piedra fundamental de la vivienda o previa la celebración de un matrimonio, se celebra la waxt'a o culto de la ofrenda. En casos de la toma de posesión de las autoridades gubernamentales, se realiza la ceremonia de la Ch'alla, que es la consagración. La Wilancha es un sacrificio vivo que se realiza una vez al año $\mathrm{y}$, en general, se celebra en la fiesta de Intiraymi con el fin de purificar la vida biológica, social, intelectual y espiritual. Finalmente, Akulli es un acto de comunión, primero entre las familias y luego entre el Dios Pachamama; ese acto se presenta en forma permanente en los demás actos litúrgicos de waxt'a, la Ch'alla y la Wilancha de la comunidad andina.
La liturgia festiva de la vida se realiza en unidades familiares de Ayllu Marka, en forma similar a la de la familia de Manuel Mamani Ruiz.

Según la explicación de los Awkinaka (ancianos), la liturgia festiva de la vida del pueblo andino cumple las siguientes funciones fundamentales:

- El mantenimiento de la fidelidad del Ayllu Marka en el Dios Pachamama.

- La renovación constante de la comunión entre las unidades familiares y el Dios Pachamama.

- El cumplimiento del compromiso de mantener el sistema de vida comunitaria en los aspectos económicos, políticos, sociales y culturales de la historia andina.

- El mantenimiento de la identidad sociocultural y una renovación permanente de la fuerza de la fe en la lucha por la resistencia ante la opresión dominante y la esperanza Pachakuti (restauración, renacimiento o retorno) de la liberación que irrumpía innegablemente en el tiempo próximo o venidero.

La liturgia festiva de la vida del pueblo en los Andes centrales funciona hoy en forma camuflada con la cruz cuando es pública, y de 
manera escondida cuando los opresores persiguen. Generalmente, es un acto interno y hasta subterráneo en los niveles locales de las unidades familiares y culturas Aymara, Qiswa, urus, chapaya. Porque el pueblo andino sabe de los grandes peligros y que puede ser aniquilado, debe optar por estrategias muy costosas, y muchas veces ceder a los agresores, por decirlo así, llevar una vivencia de un sincretismo dialéctico, porque lo importante es resistir y luego luchar por la liberación, aun con el sacrificio de la vida para sobrevivir. A esa lucha del pueblo andino y especialmente del pueblo Aymara, Fernando Montes Ruiz (1984: 293) se refiere de la siguiente manera:

"El Aymara ha logrado sobrevivir cuatro siglos y medio de dominación y desprecio a costa de enormes concesiones y sacrificios: Tuvo que agazaparse en la indiferencia y el mudo estatismo, hubo de someterse a la voluntad de quien determinaba su ruina, debió doblegarse y humillarse para eludir sus golpes, se vio obligado a frustrar sus deseos o coartar sus necesidades, a restringir su ámbito vital y a fingir ser lo contrario de lo que en realidad es; en fin, no tuvo otro remedio que renunciar al mundo para huir de sus peligros: negarse a sí mismo y a todo lo que le rodea, morir en vida para sobrevivir."
En un pueblo de presión agresiva, el andino no ha cesado en su lucha ni dejará de ser en el futuro con la fuerza de la fe de Pachamama. Su consigna es Tiwanaku Pachakuti, o sea, el renacimiento de la cultura milenaria de Tiwanaku.

De modo que, con la "liturgia festiva de la vida", el pueblo andino se ha resistido por cerca de 500 años; ahora la lucha es por la liberación hacia un nuevo hombre y una nueva sociedad: la sociedad comunitaria, fraterna y solidaria, como proyecto divino.

El funcionamiento de la "liturgia festiva de la vida" es el Yatiri fundamentalmente. A veces, pueden celebrar los ancianos de Ayllu Marka, hombre o mujer (es indiferente). Entonces, veamos acerca del Yatiri o sacerdocio andino.

\section{El Yatiri o sacerdocio andino}

Para entender su verdadero significado en el pueblo andino, vamos a explicar sus dos sentidos: el sentido de la reducción y el sentido sacerdotal.

El sentido de la reducción se refiere a que el Yatiri es confundido, involuntaria o intencionalmente, con el Laiqa Ch'amakani y Kallawaya ${ }^{16}$.

16. Laiga es brujo. Ch'amakani es considerado como exorcista. Kallawaya es médico. 
El laiqa es un brujo que funge como funcionario religioso en el pueblo andino. Su actividad principal es auxiliar a las peticiones de las personas que atraviesan crisis del tipo económico, de salud, de moral, social y judicial.

El área de acción del laiqa, generalmente, son los sectores sociales del campo rural y de las poblaciones populares de centros urbanos. Su trabajo consiste en pedir las fuerzas malignas o demoniacas, para con ellas maldecir a las personas causantes de robo, de pleitos terrenales, de las competencias de los negocios, de los problemas morales; por ello, merece el castigo y el sufrimiento como escarmiento inolvidable.

El laiqa ejerce sus funciones semirreligiosas de manera secreta $\mathrm{y}$, en general, por las noches, por lo que es aceptado en la sociedad. Los servicios de laiqa son bastante usados por muchas personas y también bien remunerados.

Por lo tanto, considerar al Yatiri o sacerdote andino como laiqa es una simple reducción, porque la función sacerdotal es mucho más que la de un brujo. De manera que, entonces, no es posible reducir o confundir la función sacerdotal con la del laiqa.

El Ch'amakani es un funcionario de tipo "exorcista". Su función principal radica en buscar la recuperación de la salud de los enfermos por medio de exorcismo. La otra es averiguar los autores de robo, de asesinato o la causa de la enfermedad, haciendo hablar a las fuerzas de las montañas (Achachilas), a los ríos, a las viviendas y hasta al espíritu del difunto. Por los servicios prestados, el Ch'amakani cobra un precio bastante alto y mucho más que un laiqa brujo.

De modo, entonces, que el Yatiri, sacerdote andino, tampoco se puede reducir ni confundir con el Ch'amakani. La función religiosa de Yatiri es más que la del Ch'amakani.

El Kallamaya (palabra Aymara castellanizada que se escribe en su sentido verdadero Qulawayu), quiere decir "médico". Su función principal es la preparación farmacéutica: una serie de medicamentos con base en plantas y para diferentes enfermedades, así como para heridas. Además de preparar los medicamentos, es un especialista y cirujano; realiza las operaciones del cuerpo humano, hasta las más delicadas como la operación cerebral, en casos cuando una persona sufre una fractura de cráneo como consecuencia de fuertes golpes.

El Yatiri tampoco se puede confundir con el Kallamaya. Precisamente, porque sus funciones son específicas. El primero es religioso y el segundo tiene una función médica. Entonces, veamos el verdadero sentido religioso del Yatiri. 
Tal como decíamos anteriormente, el Yatiri es "sacerdote" en el Ayllu Marka. Es el sacerdote andino. Es un funcionario religioso reconocido públicamente por las unidades familiares o Ayllu Marka. Tiene una función de tipo vocacional y permanente, más específicamente: es una vocación ministerial como resultado del llamado de la deidad suprema.

El llamado vocacional al sacerdocio está completado con una preparación o educación que con frecuencia se indica a la edad de 20 años aproximadamente. El proceso de aprendizaje dura hasta la edad de 40 años. En ese lapso, el candidato trabaja al lado de los Yatiri, cuando su vocación religiosa avanza progresivamente, y entonces recibe la recomendación del anciano Yatiri para que acuda por cuatro veces al santuario de Pachamama más próximo. Ahí deberá sentir la sorpresa divina mediante esas fuerzas que se manifiestan como viento tibio en algún momento del día.

Experimentar el acontecimiento de la sorpresa por cuatro veces consecutivas no es nada fácil. Constituye la verdadera prueba: algunos pueden ir a buscarla durante los 20 años y no conseguir nada. Otros pueden conseguirla incluso en menos de 5 años; esta situación permitiría el inicio de la función sacerdotal oficial en la edad más temprana, que podría ser a los 35 años.
Cómo verificar la evidencia de la manifestación de la sorpresa es un asunto delicado y corresponde solamente al interesado. Dar el testimonio tiene dos efectos contundentes: el verdadero testimonio es la bendición y podrá ejercer la función sacerdotal lleno de éxitos y, en caso de falso testimonio, el mismo interesado será objeto de maldición y nunca podrá enfrentar una felicidad en el resto de su vida.

El testimonio verdadero manifestado por el candidato al sacerdocio obedece a los principios filosóficos del pueblo andino, que está constituido por una cuatrilogía: Aski lurawimpi jakaña, chiqa arsuñana, irnaqawimpi jakaña $y$ mawawaru untata jakañ, que quiere decir: "Guardar la dignidad y respeto a sí mismo y del prójimo; dar el testimonio de la verdad, trabajar para vivir y conservar la lealtad al pueblo". En Qiswa dice: Ama súa, ama llulla, ama qilla y ama llunk'u y se traduce como "no seas ladrón, no seas mentiroso, no seas flojo y no seas traidor".

De ese modo, se explica que el testimonio del candidato al sacerdocio es una verdad, y por lo mismo merece la Ch'alla para que el nuevo Yatiri pueda ejercerlo en forma legítima y pública en el Ayllu Marka. Por cuanto en un Yatiri que ha recibido el mandato divino, es hijo del Dios Pachamama no es voluntad humana ni pertenece al 
nombramiento comunal. Al respecto, citamos lo que dicen Willaian Carter (en Xavier Albó, 1988: 480):

“...son pocos los cargos que no pasan por este mecanismo comunal de selección. La excepción más significativa es el Yatiri el que sabe, o sacerdote de la comunidad, cuyos poderes especiales no provienen del nombramiento comunal, sino de la especial selección por parte de los poderes sobrenaturales, expresados muchas veces a través del rayo."

Efectivamente, el pueblo andino sabe que el Yatiri es hijo de la deidad suprema. Sus funciones obedecen a la fuerza de la fe que viene por medio de la tierra, del cosmos universal; por lo mismo, su misión es acompañar al Ayllu Marka como un miembro más y desde la base social, en el proceso de desarrollo de la historia.

El Yatiri es el acompañante del pueblo andino. Es responsable de las actividades de la "liturgia festiva de la vida", de enseñar los principios doctrinarios a las nuevas generaciones y alentar al pueblo en la esperanza de Pachakuti de la liberación. Esto como un retorno de los nuevos tiempos, nueva historia y la nueva sociedad distinta de la vieja sociedad injusta y sufrimiento del ser humano con otro Dios opresor y anti vida. A continuación, explicaremos el significado del Dios cristiano colonial de la muerte y el Dios de la Biblia del jubileo liberador.

\section{El Dios de la cristiandad colonial}

A partir de su experiencia religiosa actual, el pueblo andino trata de entender acerca del dios de la religión cristiana en dos maneras: el Dios opresor de la cristiandad colonial y el Dios liberador de la Biblia.

\section{El Dios opresor de la cristiandad colonial}

Desde la Conquista española, el Dios de la cristiandad ha sido el principal sostén del sistema de vida colonial, basado en los valores de la cultura occidental. Dicha conquista ha sido un proceso de invasión de los procesos andinos, de dominio, de transculturación y de opresión colonial, sus efectos devastadores se han prolongado hasta el día de hoy.

La conquista española de los Andes centrales se ha hecho en nombre de Dios y apoyada con triple arma: política e ideológica, jurídica y teológica.

\section{El arma política e ideológica}

La España del siglo XV vivía los grandes efectos históricos del Occidente europeo: la pobreza económica y el sacrificio de vidas 
humanas como consecuencia de las guerras libradas contra los turcos, los árabes y los judíos.

Pero, después de las batallas libradas, la recuperación era evidente. Se consolidó la unidad nacional española, precisamente en amparo de la fe cristiana y bajo la fórmula de Dios, patria y rey, como principio político ideológico que sería el sustento principal de la colonización del Nuevo Continente. Sobre esa política e ideología de la unidad nacional de la España católica, veamos lo que dice el comentario de Gustavo Adolfo Otero (1975: 128), en su obra Vida social en el coloniaje:

"Aparece en primer término España, que alcanzó su unidad nacional abrazada de la bandera de la fe cristiana, consolidando la existencia del estado en la fórmula de Dios, patria y rey. La religión cristiana en España desde el punto de vista del estado, fue el más preciso instrumento político, conductor de voluntades, artífice de situaciones y un arma de lucha, de domino y de exaltación triunfal."

Así, podemos entender que el espíritu político e ideológico de España estaba basado en la idea absolutista del poder de Dios, el cual es transferido a la autoridad civil del rey para gobernar la nación española como pueblo elegido de Dios, tal cual fue el Israel bíblico.
La ideología de Dios, patria y rey se manifiesta en la práctica política y, por ello, el poder real estaba unido al poder de la Iglesia. Dicho de otra manera, Iglesia-estado o Iglesia-poder era la característica fundamental de la cristiandad.

La Iglesia y el Estado eran dos fuerzas poderosas políticamente; ambos poderes colaboraron mutuamente en la colonización. El Estado protegía todos los actos y el plan de evangelización de la Iglesia, en tanto que la Iglesia legitimaba todos los actos políticos del Estado. De la relación estrecha entre estos dos poderes, Pablo Richard (1987: 30) dice:

"En la cristiandad la relación Iglesia-estado, iglesia-poder, es la relación que define la articulación de la iglesia con la sociedad. La relación iglesia poder, es la estructura fundamental de la cristiandad, que orienta la presencia de la cristiandad, que orienta la presencia de la iglesia en la sociedad y que también estructura internamente la misma iglesia."

Obviamente, la Iglesia se conoce como la Iglesia de la cristiandad con sus propias características del poder espiritual unido al poder temporal del Estado, como herencia de la Edad Media de Europa Occidental.

Desde la colonización española, los dos poderes del Estado 
y la Iglesia constituían el poder uránico, de arriba, de los grupos dominantes y gubernamentales de los pueblos. Ese doble poder sustituyó el del Inka Atahualpa, que también ejercía el poder político y teocrático uránico y de arriba para abajo. En suma, el poder de Dios cristiano sustituyó el del Dios Inti o Dios Sol.

Pero el Dios Inti de Atahualpa, a pesar de su poder uránico, no usurpa derechos de los pueblos, la propiedad comunitaria, la organización del Ayllu y todo un sistema de vida comunitaria, herencia de la cultura milenaria de Tiwanaku.

En cambio, el poder de Dios de la cristiandad colonial, unido al poder del Estado, interrumpió todo el sistema de vida comunitaria andina. Usurpó las tierras a favor del individualismo y de la propiedad privada, esclavizó el Ayllu Marka, el gobierno de los Jilaqata fue sustituido por los representantes de la monarquía y luego la democracia. La religión andina fue declarada idólatra y pagana, y nunca hubo paz sino la violencia de la guerra. Al respecto, citamos lo que dice Giulio Girardi (1988: 30):

"La paz colonial, es en efecto, la sumisión de los territorios y pueblos descubiertos conseguida a base de un despliegue enorme de violencia. Ante todo, la paz colonial consiste en la expropiación sistemática del continente, en sus recursos económicos de la fuerza de trabajo: en definitiva, el desmantelamiento de su economía y su reestructuración en términos capitalistas al servicio de la madre patria.

En el terreno político, la conquista impuso con violencia los cambios que garantizarían a las potencias coloniales el control del país. Al interior de cada pais, esto significó supresión de las formas aún rudimentarias de democracia existentes; la instauración de regímenes dictatoriales apoyados por bandas armadas, considerados (justamente) más aptos para garantizar la dependencia; y la representación sistemática de los intentos de rebelión y de democratización."

De manera que el Dios de la opresión colonial tuvo su arma política e ideológica, y por ello los conquistadores lucharon bajo la ideología de Dios, patria y rey. Pero ese principio ideológico necesitaba un instrumento jurídico para que sus actos fueran legalizados. Al respecto, analizaremos adelante.

\section{El arma jurídica}

El Dios uránico y colonial usó el arma jurídica a fin de que la destrucción de la religión andina fuera legal. Desde entonces, se elaboraron las leyes que se pusieron en práctica a lo largo y ancho del Nuevo Continente. 
Con el propósito de normar la vida civil y la vida religiosa en el Nuevo Continente, se dictó un cuerpo de normas jurídicas conocidas como las Leyes de Indias. La primera de esas leyes fue dictada en 1512, según Luis Alberto Sánchez; y luego fueron modificadas y revisadas en 1513, con Carlos V. En 1526, se dictaron las leyes nuevas; en 1542, las ordenanzas de Felipe II y en 1586 se hizo la recopilación de las Leyes de Indias, y la política indiana de Solórzano se conoció en 1948. Todas esas leyes servían para normar la vida del Nuevo Mundo. Sin embargo, la bula interceptora fue promulgada por el Papa Alejandro V, el 4 de mayo de 1493, en respuesta a los teólogos que se preguntan si los hombres del Nuevo Mundo tenían alma o no. Al propósito, Alberto Sánchez (1975: 211-213) reproduce lo que dijo el Papa:

"Mucha gente que vivía en paz y tal como le habian dicho andaban desnudos y no comían carne humana. Además [...] tales gentes [...] creian en un Dios creador en los cielos y parecía suficientemente dispuesto a abrazar la fe católica y aprender las buenas costumbres. En semejantes condiciones, era de esperarse que, si se les instruía, el nombre del salvador, Nuestro señor Jesucristo, sería fácilmente acatado en dichos países e islas."
Si bien el papado de aquel tiempo trataba de respetar la vida de los indios, estos en cambio deberían ser evangelizados, bautizados y sometidos a la fe cristiana y destruidos sus santuarios religiosos. Sobre las instrucciones religiosas, se conoce en la Legislación de Indias, que fue aprobada en el año 1523 y luego revisada en 1538 y 1551 , respectivamente. De las funciones reales de ese documento, Pierre Duviols (1977: 54-55) nos trae lo siguiente:

"Que hagan derribar y derriben quitar y quiten los ídolos, aras y adoratorios de la gentilidad, y sus sacrificios, y prohiban expresamente con graves penas a los indios idolatrar y comer carne humana aunque sea de los prisioneros y muertos de guerra, y hacer otras abominaciones contra nuestra santa fe católica y toda razón natural."

Cualquier desobediencia del indio a las prácticas de la religión cristiana era penada severamente con el castigo físico, psicológico y la muerte.

El escenario español no tenía nada de malo, porque estaba ejerciendo el derecho jurisdiccional y el derecho eclesiástico. El primero es el derecho natural conferido por pisar por primera vez y establecerse en un territorio que consideraban conquistado. Por consiguiente, el español goza del derecho de 
evangelizar mediante el bautismo y la profesión de la fe cristiana como acto lícito.

En cuanto al segundo, tenía el fundamento bíblico y en las tradiciones que la Iglesia practicaba como verdades de la fe cristiana. Aquí nuevamente citamos lo que dice Pierre Duviols (1977: 54) al respecto:

"El derecho de la iglesia era indiscutible. El antiguo testamento (destruid dice el señor-los altares y quemar los bosques sagrados Ex. 34,13), el Nuevo testamento, las leyes de los emperadores cristianos de Roma, San Agustín, los concilios, etcétera, toda la historia de la iglesia era invocada por los teólogos para justificar los derechos y deberes de la extirpación."

Con base en el derecho eclesiástico, los colonizadores cristianos emprendieron la persecución de la religión andina y los sujetos sociales. Según las referencias de Pierre Duviols (1977), en Perú, este derecho comenzó a funcionar desde el año 1545, cuando el arzobispo Loayza hizo aprobar el gobierno de Gonzalo Pizarro. Se refiere a los principios básicos de la evangelización indígena y a la extirpación de las idolatrías; las tareas eran la construcción de las capillas, la celebración de los oficios y los sacramentos, la destrucción de los monumentos paganos, la condena de las idolatrías y la enseñanza católica.

Evidentemente, las leyes fueron puestas en práctica; los fieles de la religión andina han sido perseguidos, apresados, encarcelados, torturados y muertos. Los templos fueron destruidos por los mismos indígenas y los cadáveres de estos enterrados en los cementerios cristianos. Son algunas consecuencias del castigo. Tal como nos refiere Pierre Duviols (1977), quien también indica que un inicio desobediente era castigado con tres días de prisión y 50 latigazos, la primera vez; y en la reincidencia, quemada públicamente. José Comblin (s.f.: 5) nos comenta así.

"Los conquistadores y misioneros consideraron las religiones de los indígenas como bárbaras, supersticiosas e idolátricas. Pensaron que era necesario exterminarla totalmente para construir el edificio de la religión cristiana. Lo construyeron todo: templos, cleros, ritos, dogmas o mitos, costumbres, conductas, instituciones sociales o politicas ligadas a la religión. Sin embargo, Fray Bernardo de Sahagun consta que ese método ha destruido el edificio moral y formado a hombres viciosos."

Ahora, podemos comprender mejor cómo el arma jurídica legitima el derecho jurisdiccional natural y el derecho eclesiástico en el periodo colonial, así como todas 
sus repercusiones en la vida republicana de los países andinos.

El Dios de la cristiandad es un Dios egoísta, cuando se afirma que es el único Dios; es un Dios de la opresión, cuando somete a pueblos enteros y los despoja de sus valores culturales; es un Dios anti vida, cuando en su nombre matan a otros; y es un Dios racista, cuando en su nombre los blancos desprecian y marginan a los negros y a los indios. Es un Dios de los poderosos, cuando las leyes surgen de las necesidades de los dominantes; es un Dios uránico, cuando se enseña del cielo y del infierno. Entonces, ¿cuál fue la interpretación de la teología de la cristiandad colonial? Veamos adelante.

\section{El arma teológica}

Cuando llegaron al Nuevo Continente, los frailes de ayer se preguntaron y discutieron si el indio tenía alma o no; los misioneros de hoy nos intentan enseñar que sin la Biblia no hay teología. Entonces, la pregunta es: ¿qué se entendía de la teología en la época colonial y cómo entendemos la teología según la Biblia hoy?

La teología que llegó junto con Cristóbal Colón y su banda de mercenarios fue una teología de la cristiandad en tránsito hacia una teología moderna. Esa teología de la cristiandad conoció a una Iglesia cristiana en crisis, que dio finalmente el lugar al surgimiento de la Reforma Protestante y, al mismo tiempo, a una sociedad feudal también en crisis, en tránsito hacia una sociedad mercantil y luego moderna. De allí, entonces, que la teología de la cristiandad fue cuestionada por otro sujeto social: la sociedad comunitaria andina y su Dios Pachamama. Fue un verdadero encuentro de dos mundos distintos, entre el occidente europeo y el andino milenario en el sur del Nuevo Mundo. Al respecto, Gustavo Gutiérrez (1982b: 237) dice:

"Para la cristiandad occidental el encuentro con el indio americano planteó una serie de nuevos problemas en los que lo político y lo religioso se hallan fuertemente implicados. Estos problemas fueron enfrentados con las viejas categorías de la cristiandad, pero el impacto de ese otro del mundo occidental el indio, dio lugar a prácticas y reflexiones que cuestionaron la teología dominante..."

De modo que la pregunta anterior se resuelve con el análisis de Riolando Azzi (1981) sobre La teología en el periodo colonial, que consiste en "teología de la cristiandad, teología del destierro y la teología de la pasión".

La teología de la cristiandad sostiene que no hay salvación fuera de la Iglesia, lo cual significa 
que no hay salvación fuera de la sociedad colonial conquistadora y cristiana, precisamente, porque los españoles se consideraban como pueblo elegido de Dios para anunciar la salvación del mundo. La misión correspondía a la jerarquía y al clero eclesiástico. La evangelización exigía la conversión, y para el indio esta significaba el abandono total de su religión, que era considerada pagana e idólatra. También representaba el abandono y la negación de sus valores culturales y la civilización alcanzados hasta ese momento. En ese ambiente de la conquista opresiva, cualquier acción era un sacrificio por la causa del evangelio; entonces, declarar la guerra o cometer cualquier atropello al indio, se consideraba justa lucha por la santidad.

La teología del destierro da a conocer que la vida actual es pecadora, por causa del pecado original. Por lo tanto, merecemos el sufrimiento acá en la tierra, en una situación temporal hasta que llega la verdadera vida para volver a la patria perdida. La teología era ascética y espiritual, de rechazo al mundo y a las cosas materiales, porque son temporales y llenas de pecado. Hay que esperar el más allá para el gozo de la eternidad.

Por su lado, la teología de la pasión sostenía un largo camino para llegar a la salvación. Ese largo recorrido exigía la mediación de los santos, a fin de poder avanzar con más seguridad hacia la salvación. De manera que se alentaban las procesiones y romerías a los santuarios, la práctica de las cofradías y hermandades a los santos.

Con los antecedentes arriba analizados, podemos decir que la teología del periodo colonial ha sido un arma efectiva para los conquistadores. Se ha enfatizado en un Dios lejano que opera la salvación lejos de los santos, y que prescribe guardar respeto y devoción a las enseñanzas religiosas, a fin de poder llegar hasta el más allá. Es un Dios que separa al mundo social y al espiritual; de ellos, el más importante es el segundo y nada tiene que ver con el social porque es pecador y hay que separarse.

En conclusión, el Dios de la época colonial evidentemente es un Dios de la opresión. Un Dios que ha despojado de todos los bienes económicos al pueblo andino y un Dios que ha sustituido el poder político del Inka andino por el del conquistador, para someter por la fuerza de las armas. Es un Dios que ha impuesto una sociedad clasista sobre la sociedad comunitaria. Ha trasplantado los valores culturales del Occidente en lugar de los valores culturales del pueblo andino. Es un Dios egoísta que se considera único, declara idólatra y pagana a la religión Pachamama, y es un Dios legitimador de los actos 
coloniales que permitieron el genocidio humano y el etnocidio cultural del Tawantinsuyu.

La herencia de esa teología colonial opresora, contraria a la vida y partidaria de la muerte, repercute actualmente en la vida religiosa del pueblo andino. Precisamente, porque los sectores conservadores de la política imperial dominante tienden a reasumir las corrientes tradicionales de la teología colonial que ha sido falseada, manipulada y usada como un instrumento eficaz de la dominación. Pero, el verdadero Dios de la Biblia es distinto del Dios colonial.

\section{El Dios liberador de la Biblia}

La lectura andina bíblico-teológica nos ha permitido interpretar que el Dios de la Biblia es un Dios de jubileo, según la ley mosaica en el Levítico. Libera a los presos; rescata los bienes prestados o perdidos, en favor de sus antiguos dueños; y declara el descanso de la tierra en el año sabático. Por ello, el profeta Isaías proclamó en Israel que el Dios de la Biblia es un Dios de consuelo, de la reconstrucción, de la paz, de la armonía y la liberación.

Por lo tanto, los ibéricos, buscadores de las riquezas, se llevaron el oro y la plata del gran Tawantinsuyu. Legitimaron sus actos por medio de la manipulación y la distorsión del verdadero contenido del mensaje bíblico, en un Dios colonial opresor anti-vida.

Sin embargo, encontramos e interpretamos que el Dios de la Biblia es un Dios del jubileo, de la vida y liberador de los pobres. Es un Dios bíblico paradigma en el Dios Pachamama de Pachakuti, que lucha contra la opresión y anuncia la liberación comunitaria. De manera que interpretamos el mensaje de Jesús, en Lc. 4:16-22, como el paradigma de liberación genuina.

En conclusión, a través de todo este recorrido, se pudo apreciar que el dios de la cultura andina en su manifestación con la cultura colonial no se aparece. En cambio, con el Dios bíblico tienen acciones consensuadas.

\section{Bibliografía}

\section{Libros}

Aguiló, F. (1988). Tipología religiosa andina. La Paz, Cochabamba: Los Amigos del Libro.

Albo, X. (recopilador) (1988). Raíces de América: El mundo Aymara. Madrid: Alianza Editorial-América.

Bertonio, L. (1612). Vocabulario de la lengua Aymara. Lima: Impreso Compañía de Jesús Francisco del Canto de Juli.

Centro de Estudios Peruanos. (1982). Historia de los Cajamarquinos. Lima: CEP. 
Clevolet, M. (1982). Lectura materialista de la Biblia. Salamanca: Ediciones Sígueme.

Concejo Mundial de Iglesias. (1982). Venga tu reino: perspectivas misioneras. Salamanca: Ediciones Sígueme.

Comblin, J. (1988). Doctrina de seguridad nacional I. San José: Nueva Década.

Consejo Nacional de Población, Perú. (1984). Hechos y cifras demográficos. Lima: CEP.

Centro de Información de Estudios y Documentación. (1981). Acerca de la historia y el universo Aymara. Lima: CIED.

Duviols, P. (1977). La destrucción de las religiones andinas: durante la Conquista y la Colonia. México: Universidad Autónoma de México.

Eliade, M. (1970). Tratado de la Historia de las Religiones. Madrid: Ediciones Cristiandad.

Girardi, G. (1988) La conquista de América. ¿Con qué derecho? San José: DEI.

Gutiérrez, G. (1982a). La fuerza histórica de los pobres. Salamanca: Ediciones Sígueme.

Gutiérrez, G. (1982b). La teología política en el Perú del siglo XVI. Allpanchis: El Cristianismo Colonial. Cuzco: Instituto de Pastoral Andina.

Instituto Interamericano (varios escritores) (1988). Indianidad, etnocidio e indigenismo en América Latina. México: Coedición del Center de Estatus Mexicaines et Centre Americaines y el Instituto Indigenista Interamericano.

Mamani Pocoaca, M. (1998). Toponimias altiplánicas de la Paz. La Paz: C\&C Editores.
Mason, J. A. (1961). Las antiguas culturas del Perú. México: Fondo de Cultura Económica.

Metraux, A. (1975). Los Incas. Buenos Aires: Centro Editorial de América Latina.

Montes, F. (1984). La máscara de piedra: simbolismo y personalidad Aymara en la historia. La Paz: Editorial QuipusComisión Episcopal de Educación.

Monast, J. E. (1972). Los Indios Aimaraes: ¿evangelizados o solamente bautizados? Buenos Aires: Ediciones Carlos Cohlki.

Marty, E. M. (1987). Peregrinos en su propia tierra. Bilbao: Editorial Deselie de Brouwer.

Otero, G. A. (1975). Vida social en el coloniaje. La Paz: Biblioteca del Sesquicentenario de la República.

Posnansky, A. (1945). Tiahuanaco: cuna del hombre americano. New York: Editor J. J. Agustín.

Richard, P. (editor). (1981). Historia de la Teología en América Latina. San José: DEI-CEHILA.

Richard, P. (1987). La fuerza espiritual de la Iglesia de los Pobres. San José: DEI.

Rostworoweky de Diez, M. (1988). Estructuras andinas del poder. Lima: Instituto de Estudios Peruanos - IEP Ediciones.

Sánchez, L. A. (1975). América Pre-Colombina, Descubrimiento y Colonización. Madrid: EDAF.

Soldan, A.; Pennance, R.G. (compiladores) (1975). Diccionario de Economía. Barcelona: Oikos-Tau. 


\section{Revistas}

Hinkelanmert, F. (1989). Economía y Teología: Las Leyes del Mercado y la Fe. Revista PASOS. San José: DEI, mayojunio, núm. 23, 18 pp.

\section{Documentos inéditos}

Aguilar, R. (1989). Construyendo el Reino de Dios en el Compromiso Revolucionario Nicaragüense. SIMPOSIO: Impresiones de Nicaragua. Costa Rica. UNA-Escuela Ecuménica de Ciencias de la Religión. 13 de setiembre.

Consejo Mundial de Iglesias. (1975). La Iglesia y los Pobres. Nairobi: CMI.

Comblin, J. (s.f.). Valoración cristiana de las religiones nativas o sincretismo religioso. Oruro-La Paz. 
